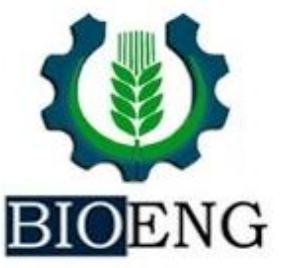

\title{
DOSES DE EXTRATO DE PRÓPOLIS NO CONTROLE DO FUNGO Aspergillus sp E NO TRATAMENTO DE SEMENTES DE PEPINO
}

\author{
BIOENG E.P. de Souza1 ${ }^{*}$, B.S. Moscato², F.H.B. Perino², P.G. Nakada-Freitas ${ }^{1}$, \\ S. Blumer ${ }^{2}$, A.I.I. Cardoso ${ }^{3}$, C.S.B. Bonini ${ }^{1}$ \\ ${ }^{1}$ UNESP - Universidade Estadual Paulista, Faculdade de Ciências Agrárias e Tecnológicas, \\ Campus de Dracena, SP, Brasil \\ ${ }^{2}$ FUNGE - Faculdades Gammon, Departamento de Produção Vegetal, Paraguaçu Paulista, \\ SP, Brasil \\ ${ }^{3}$ UNESP - Universidade Estadual Paulista, Faculdade de Ciências Agronômicas, Campus de \\ Botucatu, SP, Brasil
}

Article history: Received 29 September 2017; Received in revised form 21 November 2017; Accepted 23 November 2017; Available online 27 December 2017.

\section{RESUMO}

O controle alternativo tem como características a ausência de contaminação e toxicidade social e ambiental, e uma alternativa é o extrato de própolis, que se objetivou com este trabalho verificar o efeito de soluções de extrato de própolis no controle in vitro do fungo Aspergillus sp, e a qualidade fisiológica das sementes de pepino após o tratamento com as mesmas soluções. Isolado do fungo foi inoculado em meio BDA com concentrações de $0 ; 8$; $12 ; 18$ e $25 \%$ de extrato aquoso Propamax ${ }^{\circledR}$, totalizando cinco tratamentos. Para o tratamento das sementes foram utilizadas mesmas concentrações de extrato de própolis. $\mathrm{O}$ delineamento foi inteiramente casualizado com seis repetições. Verificou-se que com o aumento linear da dose do extrato de própolis, houve interferência no desenvolvimento do fungo atingindo máximo com dose de $25 \%$. Sementes de pepino tratadas com soluções de própolis não afetam a qualidade fisiológica, surgindo um possível tratamento alternativo de sementes.

Palavras-chave: Cucumis sativus, defensivo orgânico, qualidade fisiológica.

\section{EXTRACT OF PROPOLIS IN THE TREATMENT OF CUCUMBER SEEDS AND CONTROL OF Aspergillus sp}

\begin{abstract}
The alternative control has as characteristics the absence of contamination and social and environmental toxicity, and an alternative is the extract of propolis, which objectified with this work verify the effect of solutions of propolis extract in vitro control of the fungus Aspergillus sp, and the physiological quality of the cucumber seeds after treatment with the same solutions. Isolate from the fungus was inoculated in BDA medium with concentrations of $0 ; 8 ; 12 ; 18$ and $25 \%$ of aqueous Propamax ${ }^{\circledR}$ extract, totaling five treatments. For the seed treatment, were used the same concentrations of propolis extract. The design was completely randomized with six replicates. It was verified that with the linear increase of the dose of the propolis extract, there was interference in the fungus development reaching maximum with $25 \%$. Cucumber seeds treated with propolis solutions do not affect the physiological quality, resulting in a possible alternative seed treatment.
\end{abstract}

Keywords: Cucumis sativus, organic defensive, physiological quality. 


\section{INTRODUÇÃO}

O pepino é uma das hortaliças que vem se destacando, e ocupou o terceiro lugar do ranking em 2014 na Companhia de Entrepostos e Armazéns Gerais de São Paulo (CEAGESP), em valores de $56.856,76 \mathrm{t}$ e com participação de $6,5 \%$ nesse cenário (CEAGESP, 2014).

A cultura é propagada sexuadamente através de suas sementes. Estas são um dos principais agentes disseminadores de patógenos. Alojam determinados organismos, como fungos parasitas de sementes, a exemplo o gênero Aspergillus $\mathrm{sp}$, reduzindo a viabilidade e vigor das sementes (MIGLIORINI et al., 2011).

Para prevenção contra esses patógenos, ainda é mais utilizado o tratamento com agrotóxicos em sementes. Os antifúngicos presentes no mercado, além de gerar custos para o produtor, gera também um alto custo ambiental visto a toxicidade destas substâncias e seus efeitos prejudiciais ao meio ambiente (CESCHINI, 2011).

Os controles alternativos (SOUZA \& SOARES, 2009) têm como características o baixo potencial de contaminação e toxicidade, reduzindo os riscos à saúde. Uma das alternativas utilizadas é o uso de produtos como a própolis, caracterizandose com propriedades antifúngicas, antimicrobianas, antioxidantes, antiviral e antiprotozoária (PEREIRA et al., 2008).

Molina et al. (2008), avaliaram a atividade antifúngica de extratos naturais de própolis, mamona, sálvia e calêndula sobre 20 cepas de Candida albicans isoladas da cavidade bucal. Dentre todos os extratos testados, o que obteve maior efetividade, apresentando atividade antifúngica para todas as cepas de $C$. albicans avaliadas foi o extrato glicólico de própolis.

Vargas et al. (2014) avaliaram a ação antibacteriana in vitro da própolis em solução alcoólica a $50 \%$ sobre 161 isolados bacterianos provenientes de animais, na qual o extrato de própolis inibiu o crescimento de $67,7 \%$ das bactérias testadas.
Foram encontrados trabalhos utilizando o extrato de própolis em: cafeeiro (PEREIRA et al., 2008), quiabeiro (SOUZA et al., 2008), em plantas do pepineiro (VIEIRA \& ANDRADE, 2009), em sementes de feijão (VIEIRA et al. 2010).

Pereira et al. (2008), afirmam que a própolis tem potencial para ser utilizada no controle de ferrugem e cercosporiose do cafeeiro, não só por suas propriedades químicas, mas também como um impedimento físico para a penetração dos micélios dos fungos, devido a formação de um filme protetor sobre as folhas do cafeeiro.

Diferentemente de Pereira et al. (2008), Souza et al. (2008) ao testarem a própolis a $30 \%$ diluída contra a cercosporiose em quiabeiro, não encontraram eficiência no controle da doença. Os autores atribuem este resultado devido a não utilização de espalhante adesivo, o qual aumentaria a cobertura da folha pela calda; além da origem botânica da própolis, que interfere diretamente em sua composição química, alterando a especificidade de ação da mesma.

Vieira e Andrade encontraram potencial antifúngico para a própolis na concentração de $1,6 \%$ sobre o controle do Oídio em quatro cultivares de pepino (Híbridos F1 Nikkey, Pódium, Runner e Supremo).

Vieira et al. (2010) verificaram que os fungos dos gêneros Alternaria spp., Aspergilus spp, Cladosporium spp., Coletotrichum spp. encontrados no tegumento de sementes de feijoeiro, apresentaram redução no crescimento quando expostos a solução de própolis.

No entanto, não foram encontrados resultados no tratamento de sementes de pepino. Portanto, este trabalho objetivou verificar o efeito de doses de extrato de própolis no controle do fungo Aspergillus $\mathrm{sp}$ in vitro e, a qualidade fisiológica das sementes de pepino após o tratamento com as mesmas doses. 


\section{MATERIAL E MÉTODOS}

O experimento foi realizado em duas etapas, sendo a primeira no Laboratório de Microbiologia e a segunda no Laboratório de Sementes da Faculdade Gammon, localizada em Paraguaçu Paulista-SP, no período de agosto de 2014 a março de 2015.

$\mathrm{Na}$ primeira etapa foi estudado soluções de extrato de própolis no controle do fungo Aspergillus sp. in vitro. Os tratamentos consistiram em soluções do extrato de própolis Propamax ${ }^{\circledR}$ nas concentrações de $0 ; 8 ; 12 ; 18$ e $25 \%$.

$\mathrm{Na}$ segunda etapa foi feito o tratamento de sementes de pepino da cultivar Pepino Aodai Melhorado com as mesmas concentrações citadas anteriormente com extrato de própolis. Estas foram tratadas, agitando-se por cinco minutos (ASSIS et al., 2012), com as mesmas concentrações do extrato de própolis. Retirou-se o excesso da solução, e em seguida foram colocadas sobre papel

\section{RESULTADOS E DISCUSSÃO}

$\mathrm{Na}$ primeira etapa do estudo, verificou-se que o extrato de própolis promoveu interferência no desenvolvimento do fungo Aspergillus sp, à medida que aumentou a dose de extrato de própolis, diminuiu o crescimento micelial do fungo (Figura 1), conferindo o efeito antifúngico, o que também foi verificado por Pereira et al. (2008), nesse caso in vivo. Estes autores verificaram o efeito antifúngico do extrato etanólico de própolis, em que o mesmo diminuiu a incidência e a severidade da cercosporiose em mudas de cafeeiro e a incidência de ferrugem e cercosporiose em lavouras cafeeiras adultas, apresentando uma redução linear na incidência da doença com o aumento das concentrações do extrato na calda de pulverização. toalha permanecendo em câmara fria por um dia para secagem.

As características avaliadas foram: germinação e vigor (primeira contagem de germinação e comprimento da parte aérea e raiz). Para o teste de germinação e primeira contagem de germinação adotouse a metodologia de Brasil (2009). Para avaliação do comprimento de parte aérea e raiz, foram amostradas 10 plântulas normais do teste de germinação medidas com auxílio de uma régua, expresso em centímetros (GUEDES et al., 2013).

Nas duas etapas do estudo o delineamento experimental adotado foi inteiramente casualizado com seis repetições.

Os dados foram submetidos à análise de variância pelo teste $\mathrm{F}$ a $5 \%$ de probabilidade, e em caso de significância, as médias foram comparadas através da análise de regressão, ao mesmo nível de probabilidade.

Vieira e Andrade (2009) também verificaram atividade antifúngica do oídio (Sphaerotheca fuliginea) na cultura do pepino ao utilizarem o extrato de própolis na concentração de $1,6 \%$.

$\mathrm{Na}$ segunda etapa do trabalho, não houve diferença significativa para germinação, primeira contagem e comprimento de parte aérea (Tabela 1). Estudo realizado por Vieira et al. (2010) também não detectaram efeito sobre a qualidade fisiológica de sementes de feijão.

Diferentemente para o comprimento de raiz de plântulas de pepino, verificou-se que as sementes tratadas com solução de extrato de própolis, foram beneficiadas pelas soluções de própolis, atingindo maior comprimento na dose de 15\% (Figura 2). 


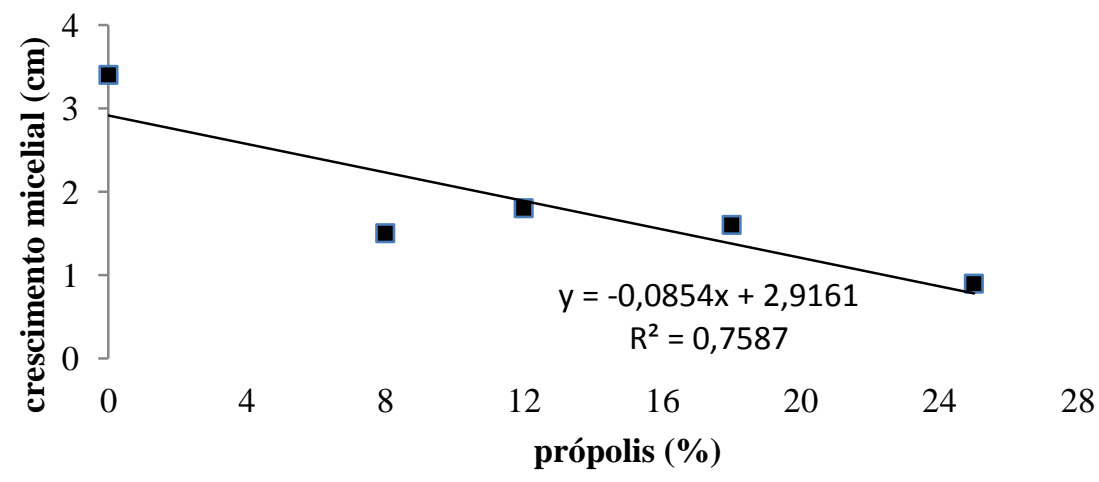

Figura 1. Crescimento micelial do fungo Aspergillus sp desenvolvido em função de diferentes doses de extrato de própolis. Paraguaçu Paulista, 2014.

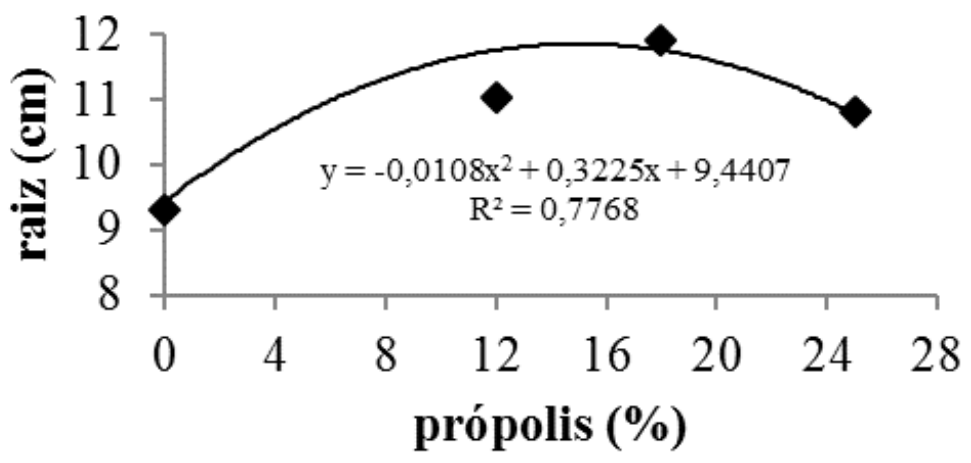

Figura 2. Comprimento da raiz de plântulas de pepino em função do tratamento de sementes de pepino com diferentes doses de extrato de própolis. Paraguaçu Paulista, 2014.

Tabela 1. Germinação, primeira contagem de germinação e comprimento de parte aérea (CPA) em função do tratamento de sementes de pepino com diferentes doses de extrato de própolis. Paraguaçu Paulista, 2014.

\begin{tabular}{cccc}
\hline $\begin{array}{c}\text { Solução de } \\
\text { própolis }(\%)\end{array}$ & Germinação $(\%)^{*}$ & $\begin{array}{c}\text { Primeira contagem de } \\
\text { germinação }(\%)^{*}\end{array}$ & $\begin{array}{c}\text { Parte aérea de } \\
\text { plântula }(\%)^{*}\end{array}$ \\
\hline 0 & 84 & 75 & 8,8 \\
\hline 8 & 90 & 87 & 8,7 \\
\hline 12 & 85 & 82 & 7,7 \\
\hline 18 & 82 & 81 & 10,1 \\
\hline 25 & 88 & 75 & 9,4 \\
\hline CV $^{* *}$ & 8,5 & 10,7 & 16,8 \\
\hline
\end{tabular}

*Não significativo a $5 \%$ de probabilidade.

**Coeficiente de variação.

\section{CONCLUSÕES}

O extrato de própolis na dose de $25 \%$ proporcionou interferência no desenvolvimento do fungo Aspergillus sp impedindo a sua proliferação, como também não afetou a qualidade fisiológica de sementes de pepino. 


\section{REFERÊNCIAS}

ASSIS, M.O.; RODRIGUES, B.R.A.; DAVID, A.M.S.S.; CANGUSSÚ, L.V.S.; MOTA, W.F. 2012. Potencial fisiológico de sementes de coentro e resposta ao tratamento com fertilizante à base de zinco e molibdênio. Horticultura Brasileira, v. 30, p. S7867-S7874. 2012.

BRASIL. Ministério da Agricultura, Pecuária e Abastecimento. Regras para análise de sementes. Brasília: Mapa/ACS, 2009. 399p.

CEAGESP, 2014. Disponível em: <http://www.acessoainformacao.gov.br/sis tema/Principal.aspx>. Acesso em: fevereiro de 2015.

CESCHINI, V.C. Potencial antifúngico de extratos de folhas de Eucalyptus staigeriana F. Muell. sobre Aspergillus flavus. 97f. Dissertação. (Mestrado em ciências) - Escola Superior de Agricultura "Luiz de Queiroz", Piracicaba, 2011.

GUEDES, R.S.; ALVES, E.U.; COSTA, E.M.T.; SANTOS-MOURA, S.S.; SILVA, R.S.; MIGLIORINI, P.; MUNIZ, M.; MULLER, J.; NOAL, G.; POLLET, C.S.; BASTOS, B.O. ; SILVA, T.A.; SUZANA, C.S. Qualidade sanitária de sementes de Brassica napus produzidas no Estado do Paraná. In: SIMPÓSIO DE ENSINO, PESQUISA E EXTENSÃO, 16., 2012, Santa Maria Anais... Santa Maria: Unifra, 2012.

MOLINA, F.P.; MAJEWSKI, M.; PERRELA, F.A.; OLIVEIRA, L.D.; JUNQUEIRA, J.C.; JORGE, A.O.C. Própolis, sálvia, calêndula e mamona atividade antifúngica de extratos naturais sobre cepas de Candida albicans. Cienc
Odontol Bras abr./jun.; 11 (2): 86-93, 2008.

PEREIRA， S.C.; GUIMARÃES， R.J.; POZZA, A.; SILVA, E.A. Controle da cercosporiose e da ferrugem do cafeeiro com extrato etanólico de própolis. Revista Ceres, Viçosa, v. 55, n. 5, p. 369-376. 2008.

SOUZA, L.A. Efeito fungicida da própolis e do leite sobre a cercosporiose na cultura do quiabeiro (Abelmoschus esculentus). Revista Brasileira de Agroecologia, Porto Alegre, v. 3, suplemento especial, 2008.

VARGAS, A.C.; LOGUERCIO, A.P.; WITT, N.M.; COSTA, M.M.; SILVA, M.S.; VIANA, L.R. Atividade antimicrobiana "in vitro" de extrato alcóolico de própolis. Ciência Rural, Santa Maria, v.34, n.1, p.159-163, jan-fev, 2004.

VIEIRA; G.H. da C.; ANDRADE, W.P. Efeito fungicida de produtos alternativos no controle de oídio em pepineiro. Omnia Exatas, Adamantina. v. 2, n. 2, p.45-49, 2009.

VIEIRA, G. H. da C.; DARDANI, P.; ANDRADE, W. da P.; BARBOSA, C. A. F. 044-Efeitos do extrato de própolis sobre a qualidade sanitária e fisiológica de sementes de feijão. Resumos do III Seminário de Agroecologia de MS. Cadernos de Agroecologia, Vol 5 N.1, 2010. Disponível em: <http://www.abaagroecologia.org.br/revistas/index.php/cad/ article/view/10170/6843>. Acesso em: 27 nov. 2014. 